\title{
A Teoria das Molduras Relacionais (RFT) e a Linguística de Noam Chomsky: uma aproximação possível?
}

\section{Relational Frame Theory and Noam Chomsky's Linguistics: A possible approach?}

\section{La Teoría de las Molduras Relacionales y la Lingüística de Noam Chomsky: ¿una aproximación posible?}

\author{
Jaume Ferran Aran Cebria1, Gleice Magalhães de Oliveira
}

Resumo: A “Resenha” do "Comportamento Verbal”, de B. F. Skinner, publicada por Noam Chomsky em 1959, criou uma cisão profunda e duradoura entre a Linguística e a Análise do Comportamento. Considerando as mudanças no estudo da linguagem trazidas pela Teoria das Molduras Relacionais (RFT) e a disposição explícita da Ciência Comportamental Contextual para colaborar com outras áreas do conhecimento, o objetivo do presente estudo consistiu em analisar a possibilidade de diálogo, identificando convergências e divergências, entre a Linguística de matriz chomskyana e a RFT. Diversos pontos de convergência entre ambas perspectivas foram encontrados, a maioria dos quais não seriam possíveis partindo dos pressupostos skinnerianos. Contudo, profundas divergências, principalmente de ordem epistemológica, persistem ainda. Portanto, apesar das aproximações mencionadas, não é claro como poderia ser articulada uma colaboração significativa e produtiva para ambas abordagens.

Palavras-chave: Linguagem, Noam Chomsky, Teoria das Molduras Relacionais.

Abstract: The "Review" of Skinner's "Verbal Behavior", published in 1959 by Noam Chomsky, created a profound and durable divide between Linguistics and the Analysis of Behavior. Considering the changes in the study of Language brought about by Relational Frame Theory (RFT) as well as the explicit willingness of Contextual Behavioral Science to collaborate with other fields of knowledge, the aim of the present paper is to analyze the possibility of a dialog, by identifying convergences and divergences, between chomskyan linguistics and RFT. Several convergence points between both perspectives were found, most of which wouldn't be possible from Skinnerian tenets. However, profound divergences, mainly of an epistemological character, still persist. Therefore, in spite of the approach aforementioned, it is not clear in what manner a meaningful and productive collaboration for both approaches could be articulated.

Keywords: Language; Noam Chomsky; Relational Frame Theory 
Resumen: La reseña de "Conducta Verbal" de Skinner, publicada en 1959 por Noam Chomsky creó una escisión profunda y duradora entre la Lingüística y el Análisis de la Conducta. Considerando los cambios en el estudio del lenguaje introducidos por la Teoría de las Molduras Relacionales y la disposición explícita de la Ciencia Conductual Contextual para colaborar con otros campos del conocimiento, el objetivo del presente artículo es analizar la posibilidad de diálogo entre la lingüística chomskyana y la Teoría de las Molduras Relacionales. Diversos puntos de convergencia entre ambas perspectivas fueron encontrados, la mayoría de los cuales no seria posible partiendo de los presupuestos skinnerianos. Sin embargo, profundas divergencias, principalmente de tipo epistemológico, aún persisten. Por tanto, a pesar de la mencionada aproximación, no está claro de qué forma podría ser articulada una colaboración significativa y profunda para ambas aproximaciones.

Palabras clave: Lenguaje; Noam Chomsky; Teoría de las Molduras Relacionales. 
Um dos principais momentos na tentativa de elucidação científica dos fenômenos relativos à linguagem é, sem dúvida, a publicação do magnum opus de Skinner (1957), intitulado "O Comportamento Verbal”. Nessa obra, o autor americano realiza uma extensa crítica das explicações da linguagem baseadas na ideia de referência e advoga por uma interpretação funcional da linguagem. A ideia de referência, de forma geral, implica que a linguagem constitui a expressão de ideias que, de alguma forma, representam a realidade, e essa realidade exerceria, por tanto, uma influência causal, direta ou indireta (caso admitíssemos o passo intermediário das ideias), na emissão das falas dos diferentes indivíduos. A interpretação funcional postulada pelo criador do Behaviorismo Radical implica que a linguagem é melhor compreendida em termos de comportamento operante e, dessa forma, instâncias particulares de linguagem, ou episódios verbais, podem ser explicadas cientificamente a partir das relações funcionais entre as respostas verbais, suas consequências e seus antecedentes.

Com o intuito de fugir de teorizações meramente especulativas e esclarecer essas relações funcionais, Skinner (1957) desloca o foco de atenção tradicionalmente recebido pela linguagem, definindo-a apenas de passagem como "as práticas de uma comunidade verbal" e coloca o holofote no comportamento do falante. O entendimento funcional da linguagem proposto por Skinner (1957), que começa a tomar forma pelo menos uma década antes (Skinner, 1945/ 1984) está em sintonia com um movimento mais amplo que se dá também no âmbito da filosofia da linguagem (e.g., Austin, 1955/1962). Um caso paradigmático é aquele protagonizado pelo filósofo Ludwig Wittgenstein, cuja obra (Wittgenstein, 1922/1968) passou de ser a inspiração do Círculo de Viena, cujos membros adotavam posições claramente referencialistas e representacionistas da linguagem, a ser um dos principais defensores da natureza pragmática da linguagem com sua obra póstuma (Wittgenstein, 1953/2014). De acordo com Willard Day (1969), as semelhanças entre a visão skinneriana da linguagem e aquela adotada pelo segundo Wittgenstein são remarcáveis.

Apesar de Skinner ter embasado sua interpretação do comportamento verbal em princípios bem estabelecidos experimentalmente, ela não foi bem recebida no âmbito da linguística. Noam Chomsky, professor do MIT, conhecido como o pai da linguística moderna, escreveu uma resenha da obra skinneriana bastante extensa e extremamente crítica.

A resenha de Chomky (1959) - referida como "Resenha", de agora em diante -, mais do que uma crítica específica acerca do livro de Skinner, em muitas instâncias toma o caráter de um ataque em larga escala contra a idoneidade da perspectiva comportamental para o estudo do comportamento humano. Dessa forma, Chomsky (1959) questiona a validade fora do laboratório de conceitos básicos como estímulo e resposta, afirma que a abordagem skinneriana desconsidera totalmente o organismo ou que o reforço não é necessário para que ocorra a aprendizagem. Portanto, cabe dizer que as críticas de Chomsky apresentam equívocos, como entender o reforço apenas como procedimento e não como processo, ignorar a diferença entre resposta e operante, ou atribuir a Skinner posições que ele não defende, mas que pertencem a versões anteriores do Behaviorismo.

Dada a importância da "Resenha", Bandini e de Rose (2010) realizaram uma contextualização do livro de Skinner (1957) e da resposta de Chomsky (1959), e contestaram, com base no próprio texto skinneriano, a crítica central formulada pelo linguista: a suposta incapacidade da Análise do Comportamento de explicar a "geratividade" da Linguagem, entendida como a capacidade de um falante de produzir falas, apropriadas ao contexto, que não foram previamente ensinadas.

De acordo com Bandini e de Rose (2010), é possível explicar a emissão de novas respostas verbais com base nos seguintes processos: generalização de controle de estímulos, recombinação de unidades mínimas, recombinação de fragmentos de respostas, autoclíticos e modelagem de respostas operantes.

Bandini e de Rose (2010), porém, interpretam o conceito de "novas respostas verbais" de uma forma relativamente restrita, podendo elas acontecer, a nível operante, apenas em duas situações: quando a resposta é nova para toda a comunidade linguística e quando a topografia da resposta já existe no repertório do falante, mas é emitida sob outras variáveis controladoras. Cabe argumentar, contudo, 
que esses dois casos específicos não esgotam o que Chomsky (1959) entende por "respostas novas".

A "Resenha" criou, ou ao menos explicitou, uma cisão profunda entre as investigações científicas sobre a linguagem produzidas na perspectiva da Análise do Comportamento e aquelas produzidas no âmbito da linguística, que ainda não foi superada. Considerando que a Teoria das Molduras Relacionais trouxe importantes modificações e avanços na compreensão da linguagem (De Houwer, 2013) e a disposição para encontrar âmbitos de colaboração com outras áreas do conhecimento (e.g., Biglan, 2016), o objetivo do presente estudo consiste em discutir a possibilidade de construir pontes entre a Teoria das Molduras Relacionais e a Linguística de matriz chomskyana, a partir da identificação de pontos de concordância entre ambas perspectivas e possíveis divergências. Para a consecução do objetivo proposto, foi analisado o livro de Noam Chomsky (2018) intitulado "Que tipo de criaturas somos nós?", em que sumariza os principais achados e problemáticas da sua longa carreira, assim como a obra em que a Teoria das Molduras Relacionais foi inicialmente apresentada (Hayes, Barnes-Holmes \& Roche, 2001), e outras que desenvolvem e atualizam seus pressupostos e resultados.

\section{Análise}

Apesar da diversidade de críticas formuladas na "Resenha", como já foi notado por Bandini e de Rose (2010), uma delas adquire maior proeminência se consideramos a própria teorização do linguista americano. De acordo com Chomsky (2018), a Linguagem possui uma "Propriedade Básica", entendida como a capacidade de construir um arranjo ilimitado de expressões estruturadas, possuindo cada uma delas uma interpretação semântica que expressa um pensamento e que pode ser externalizada mediante alguma modalidade sensorial. O eminente linguista americano, nesta obra de 2018, traça noções de linguagem precursoras da "Propriedade Básica", que na formulação chomskyana parece praticamente indistinguível da própria concepção de linguagem, em diversos momentos da história do pensamento filosófico e cien- tífico. Inicialmente, é citada uma fala de Darwin no sentido de que o ser humano difere dos animais inferiores por causa da sua "capacidade quase infinitamente superior" (Chomsky, 2018, p.28) de associar sons e ideias. Contudo, existem formulações anteriores. Para Chomsky (2018),

o reconhecimento e a preocupação como o caráter criativo do uso normal da linguagem logo se tornaram um elemento central da ciência/ filosofia cartesiana; na verdade, um critério primário para a existência da mente como uma substância separada (p. 34).

Desse modo, resulta manifesto um certo grau, ao menos, de identificação do renomado linguista com o racionalismo cartesiano, assim como com as ideias evolucionistas. Talvez, a posição inatista de Chomsky, discutida posteriormente neste texto, tenha relação com esta base filosófica.

Chomsky (2018) elenca também, e critica, concepções de Linguagem que desconsideram os elementos de criatividade ou geratividade próprios da Propriedade Básica. Cabe entender, portanto, suas críticas ao "Comportamento Verbal" de Skinner dentro desse contexto mais amplo de rejeição de todos aqueles modelos que apresentem formulações não condizentes ou distantes dessa noção nuclear e fundamental para o estudo da linguagem que vem sendo formulada e modificada desde a década de 1950 .

\section{Produtividade e Dupla Articulação}

Nesse sentido, para Chomsky (2018), o que é fundamental na Linguagem é a caraterística da produtividade, ou seja, a capacidade de criar uma quantidade virtualmente infinita de formas significativas de expressão a partir de um conjunto relativamente limitado de elementos básicos (os fonemas de cada língua). Essa caraterística pode ser encontrada em outros autores (e.g., Escandell, 2018) como dois aspectos distintos: a capacidade de combinar elementos simples para criar unidades maiores e de separar unidades complexas em unidades menores é chamada de "dupla articulação" e o termo "produtividade" designa especificamente a capacidade de produzir e interpretar mensagens que o sujeito nunca tinha produzido ou interpretado previamente. 
Esses dois aspectos fundamentais da Linguagem são considerados pela Teoria das Molduras Relacionais, que postula que a Linguagem pode ser cientificamente estudada como Responder Relacional Arbitrariamente Aplicável (RRAA). De acordo com Hayes et al. (2001), o RRAA é um tipo de comportamento operante que consiste em responder a relações entre estímulos estabelecidas de forma arbitrária (independentemente das propriedades físicas dos estímulos envolvidos na relação). Blackledge (2003) ainda acrescenta que se trata de um responder relacional "derivado", ou seja, que não foi diretamente ensinado, mas que emerge a partir do treino de outras respostas relacionais. Nesse sentido, é relevante mencionar as três propriedades fundamentais do RRAA: a implicação mútua, a implicação mútua combinatória e a transformação de função. A primeira delas expressa a bidirecionalidade das relações estabelecidas entre os estímulos, de forma que se for ensinado, por exemplo, que "A é maior que B" um ser humano verbalmente competente facilmente consegue derivar a relação complementar "B é menor que A". A implicação mútua combinatória segue a mesma lógica, mas envolve, no mínimo, três estímulos, aumentando em grande medida, consequentemente, o número de relações que podem ser derivadas (e.g., se "A é maior que B" e "B é a maior que C", logo "A é maior que C" e "C é menor que A"). A transformação das funções de estímulo significa que quando um estímulo "A" é relacionado a outro estímulo "B", as funções desses estímulos variam de acordo com o tipo de relação estabelecida entre eles. Por exemplo, caso seja treinada uma relação arbitrária tal que "A é maior que B", se posteriormente for treinada uma função aversiva para o estímulo "B", automaticamente, o estímulo "A" pode adquirir uma função aversiva de maior intensidade que a do estímulo "B". Esse tipo de fenômeno foi demonstrado experimentalmente por Dougher et al. (2007), usando leves choques elétricos como estimulação aversiva e medindo a reação galvânica da pele que os participantes no estudo apresentavam perante estímulos visuais arbitrariamente relacionados com aquele que foi pareado com os choques.

A respeito da produtividade, Hayes e Long (2013) explicam como um ser humano consegue, a partir de oito relações signo-objeto derivar muitas outras, sem um limite preestabelecido, com base nas propriedades de implicação mútua e implicação mútua combinatória, podendo gerar milhares de relações. Isso é diferente no caso de animais infra-humanos, que cujo repertório se limitaria a essas oito relações que lhes foram diretamente ensinadas ou, caso fossem treinadas comparações não arbitrárias, é possível que os oito objetos pudessem vir a ser relacionados mutuamente de forma não arbitrária, dando lugar a um máximo de 56 relações.
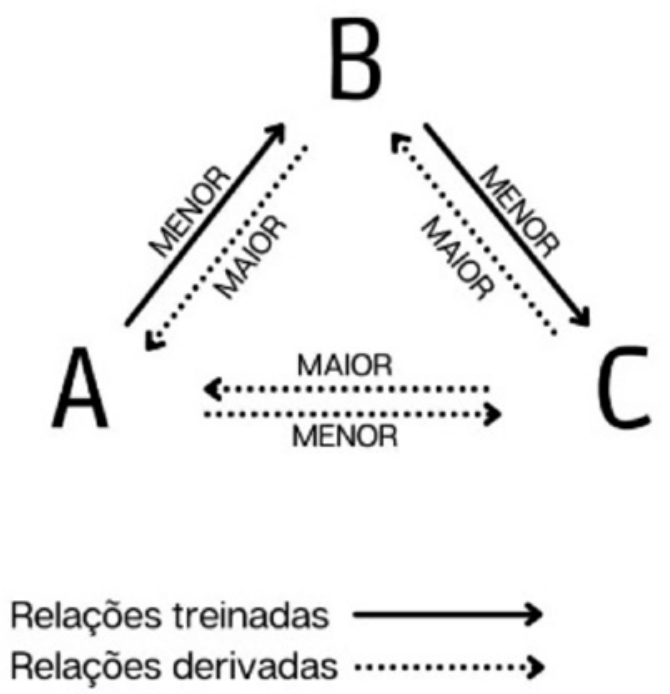

Figura 1

Com relação à dupla articulação, quando Hayes et al. (2001) explicam o conceito geral de Molduras Relacionais, afirmam que todo operante contém outros operantes e que qualquer operante pode "se expandir" em operantes maiores. Portanto, cabe pensar que a principal objeção que Chomsky colocou contra a obra de Skinner perde seu sentido quando é contrastada com as posições explicitamente defendidas pela Teoria das Molduras Relacionais, o que elimina um importante ponto de fricção entre ambas abordagens. 


\section{Linguagem e Comunicação Animal}

Outro ponto importante de coincidência consiste na consideração da Linguagem como uma caraterística específica da espécie humana, marcadamente diferente da comunicação animal. Efetivamente, Chomsky (2018) postula que a Linguagem possivelmente seja uma aquisição evolucionaria recente (entre 100.000 e 50.000 anos atrás), caraterística da espécie humana, que teria constituído um salto evolutivo, em lugar de ser resultado do acúmulo progressivo de pequenas modificações. Segundo o linguista americano, a propriedade básica não se encontra em nenhuma outra espécie animal. Escandell (2018) ainda especifica certas importantes propriedades da linguagem que não estão presentes nos sistemas de comunicação de animais infra-humanos. Elas são três:

a) Deslocamento. A linguagem nos permite fazer referência a entes ou acontecimentos não observáveis diretamente ou até inexistentes, pois as possibilidades combinatórias permitem qualquer encadeamento, desde que respeite certas regras estruturais. Por tanto, a atividade linguística não está necessariamente vinculada ao presente nem é desencadeada inevitavelmente pelas condições específicas do ambiente imediato, ao contrário do que acontece na comunicação animal.

b) Dupla estruturação. Essa caraterística, que já foi mencionada, implica que é possível construir mensagens progressivamente mais complexas a partir de um conjunto inicial muito limitado (entre 24 e 36 fonemas) de elementos.

c) Produtividade, que consiste na capacidade de construir e interpretar novos signos. Nada semelhante acontece nos sistemas de comunicação animal, que não permitem a combinação de uns signos com outros, constituindo códigos simples.

A Teoria das Molduras Relacionais afirma que o Responder Relacional Arbitrariamente Aplicável (RRAA), a nomenclatura operacional da Linguagem, é um tipo de comportamento operante típico da espécie humana, cuja existência não tem sido demonstrada consistentemente em outras espécies, que possuiriam apenas elementos do RRAA em nível rudimentar. Nesse sentido, Hayes (1989) discute os resultados de dois estudos prévios (McIntire et al., 1987; Vaughn, 1988) que relataram ter demonstrado relações de equivalência (relações simbólicas) em macacos e pombos, respectivamente. Não é o intuito do presente trabalho discutir essa questão em profundidade; mas, de acordo com Hayes (1989), além de problemas conceituais, os estudos mencionados apresentam falhas metodológicas relevantes de forma que não é possível afirmar que os animais desses estudos demostrassem realmente algum tipo de comportamento simbólico, porque todas as relações que eles exibiram tinham sido diretamente treinadas. No mesmo sentido se pronunciam Hayes et al. (2001)

... muito do que sabemos em psicologia comportamental deve ser reexaminado agora no contexto do processo de emoldurar relacional. Isso não seria tão ameaçador para a tradição que deu origem à presente abordagem, se os não humanos pudessem adquirir prontamente o responder relacional arbitrariamente aplicável. Aparentemente não podem (p. 49).

Hayes e Long, (2013) consideram, ainda, que a cognição humana, caracterizada pela capacidade de pensamento simbólico, se apresenta unicamente na nossa espécie. Outros estudos (Dube et al., 1993; Hughes \& Barnes-Holmes, 2014) que tratam especificamente esta questão apresentam conclusões na mesma linha apontada por Hayes (1989): não há dados que demonstrem a existência de RRAA nem comportamento simbólico em animais, a não ser em forma rudimentar e como produto de treino muito extenso.

Essa posição contrasta com a postulada por Skinner (1957), cuja definição de comportamento verbal não exclui comportamentos de outras espécies, e, por esse motivo, ficou mais distante da posição de Chomsky. Skinner, na verdade, ao longo da sua extensa produção, coloca grande ênfase na ideia de continuidade entre as espécies, um dos pilares fundamentais da sua explicação do Comportamento Verbal (1957). Entretanto, Hayes et al. (2012), postulam de forma explícita que os 
princípios de aprendizagem elaborados apenas a partir de estudos com animais infra-humanos não são suficientes para compreender os fenômenos linguísticos, como no trecho a seguir:

A pesquisa básica em análise do comportamento continua focando primariamente em aprendizagem animal em lugar de funcionamento humano - uma tendência que inclusive pode estar aumentando [...] apesar da evidência de que o comportamento simbólico constitui um processo comportamental novo e caracteristicamente humano que não pode ser completamente modelado usando estudos não humanos (p. 3).

Nesse sentido, Hayes (1987) apresenta uma importante distinção entre continuidade "ascendente" entre espécies e continuidade "descendente". Enquanto a primeira, que envolve a ideia de que princípios que funcionam com animais infra-humanos devem funcionar também com pessoas, é considerada provável por Hayes (1987), a segunda, que funcionaria no sentido inverso, é considerada bastante incerta pelo mesmo autor.

\section{Linguagem e Pensamento}

Em terceiro lugar, Chomsky (2018) enfatiza a ideia de que a comunicação não constitui a principal função da linguagem. Efetivamente, na concepção chomskyana, a chamada "Língua I", cujo "I" representa as noções de "Interior", "Individual" e "Intensional", possui primazia sobre a "Língua E", que seria apenas uma externalização da anterior. Com essa primazia da Língua I, o pesquisador americano parece endossar a existência de certa identidade entre linguagem e pensamento, proposta ao longo da história por pensadores de diferente cunho, como Galileu, Descartes, Darwin e Humbolt (Bilgrami, 2018). De acordo com Chomsky (2018),

cada língua incorpora um procedimento computacional que satisfaça a Propriedade Básica. Portanto, uma teoria da linguagem é, por definição, uma gramática gerativa, e cada língua é o que chamamos, em termos técnicos, uma língua-I (p. 30).
A RFT, mesmo reconhecendo a existência de processos cognitivos independentes da linguagem (como responder a relações entre propriedades formais de dois estímulos), postula que o Responder Relacional Arbitrariamente Aplicável é o processo nuclear para explicar tanto os fenômenos tradicionalmente considerados como linguísticos quanto a cognição propriamente humana. Nesse sentido, Hayes et al. (2001), explicam:

Considere o caso da transformação de estímulos. Um estímulo discriminativo é um estímulo na presença do qual houve uma maior probabilidade de reforço para um dado comportamento do que na sua ausência. Suponha que uma criança é recompensada por acenar com mão quando a palavra "cachorro" é ouvida. A palavra "cachorro" é um estímulo discriminativo. Suponha, porém, que a criança é ensinada agora a dizer "cachorro" dada a palavra C-AC-H-O-R-R-O, e a apontar a cachorros reais dada a palavra C-A-C-H-O-R-R-O. Suponha que como resultado deste treino a criança agora acena ao ver um cachorro. Tal resultado tem sido visto repetidamente na literatura. (e.g., Hayes et al., 1987). O cachorro não pode ser um estímulo discriminativo porque a criança não tem uma história de maior reforçamento para acenar na presença de cachorros do que na ausência de cachorros. Esse efeito não pode ser generalização de estímulos porque não há propriedades formais compartilhadas entre a palavra e cachorros reais. $\mathrm{O}$ efeito não pode ser devido a condicionamento clássico porque isso requereria um apelo a condicionamento reverso. Também não pode ser explicado devido a um efeito de pareamento porque "cachorro" e cachorros nunca foram apresentados juntos. A RFT sugere que esse comportamento se deve a um processo aprendido que transformou essas funções discriminativas. No controle discriminativo normal, a função de estímulo é aprendida, mas não o próprio processo. Em contraste, o comportamento derivado é 'como se fosse' discriminativo, mas não é discriminativo. Estes efeitos 'como se fossem' discriminativos parecem depender de um processo aprendido de alterar processos comportamen- 
tais e isso não é designado por nenhum termo técnico existente. Apesar do conservadorismo de uma abordagem RFT, portanto, um novo tipo de processo comportamental é sugerido e um novo termo técnico é oferecido. O novo processo é o responder relacional arbitrariamente aplicável (ou emoldurar eventos de forma relacional). Por causa de relações verbais e o responder relacional arbitrariamente aplicável ser sinónimos, o termo 'verbal' pode ser suficiente para este novo processo, desde que o termo seja usado aqui no sentido técnico. O novo termo técnico é moldura relacional. Portanto, em nossa análise, os eventos verbais (e molduras relacionais) instanciam um novo processo comportamental (p. 45).

\section{Adesão ao Paradigma Evolutivo}

Um quarto ponto que permite aproximar ambas abordagens é a relação de ambas com a Ciência Evolutiva. A Teoria das Molduras Relacionais, que constitui uma parte da estratégia conhecida como Ciência Comportamental Contextual, se insere naturalmente dentro das chamadas Ciências da Evolução (Hayes \& Long, 2013; Monestès, 2016). Chomsky (2018) adere também sem reservas ao paradigma selecionista/evolucionário, embora considere que o surgimento da Linguagem foi abrupto e súbito, de forma que poderíamos considera-lo como um caso de equilíbrio pontuado, utilizando a terminologia dos biólogos evolucionistas Niles Eldredge e Stephen J. Gould (1972). Nesse sentido, o próprio Chomsky (2018) comenta:

...um dos principais cientistas que se dedicam ao estudo da evolução humana, Ian Tattersall. Em uma revisão recente das evidências científicas atualmente disponíveis, ele observa que uma vez se acreditou que o registro evolutivo produziria precursores precoces de nós mesmos. A realidade, no entanto, é bem diferente, pois está se tornando cada vez mais claro que a aquisição da sensibilidade [humana] única e moderna foi, em vez disso, um evento abrupto e recente. E a expressão dessa nova sensibilidade foi quase certamente apoiada de maneira crucial pela invenção do que é talvez a única coisa mais notável sobre o nosso eu moderno: a linguagem (p. 29).
Considerando essas posições, a abordagem chomskyana e a da Teoria das Molduras Relacionais não seriam apenas compatíveis, mas poderiam fornecer explicações complementares, pois diversos trabalhos (Hayes \& Long, 2013; Hayes \& Sanford, 2014) levantam a hipótese de que a cooperação entre indivíduos humanos possa estar na origem do comportamento relacional derivado e, portanto, a linguagem não teria surgido abruptamente de um "vazio evolutivo". Em palavras de Hayes e Long (2013)

O contexto cooperativo fornece um motivo para o treino social e um motivo pronto para um processo contínuo de evolução genética, comportamental e cultural. Um grupo que tivesse apenas uns poucos falantes e ouvintes competentes na reversibilidade de papeis teria vantagem na sua habilidade de cooperar para completar tarefas, mas só se pudessem responder a símbolos com reversibilidade de papeis. Isso fornece uma forma muito mais plausível do ponto evolucionário de criar uma comunidade verbal capaz de modelar o responder relacional derivado (p. 15).

\section{Linguagem como Processo}

Chomsky (2018) postula que por causa da Propriedade Básica antes mencionada (a capacidade de construir um arranjo ilimitado de expressões estruturadas e com valor semântico, a partir de um número limitado de elementos), toda teoria da linguagem seria uma "gramática gerativa". De acordo com o famoso linguista, a Propriedade Básica da linguagem implica a existência de processos computacionais internos. Esses processos de tipo computacional seriam o objeto de estudo próprio da Linguística e não os produtos gerados por esses processos. De acordo com Chomsky (2018), "Estamos interessados em descobrir o processo computacional real; não algum conjunto de objetos enumerado por tal procedimento" (p. 30) e, ainda, “...a tarefa primordial é investigar a verdadeira natureza das interfaces e dos procedimentos gerativos que os relacionam em várias línguas-I e determinar como elas surgem na mente como são usadas..." (p. 36).

Semelhantemente, a RFT explicitamente propõe estudar os eventos verbais como atividade e 
não como produtos (Hayes et al., 2001), ou seja, entende a Linguagem como um tipo de comportamento operante. O RRAA, o próprio comportamento relacional derivado, é o objeto próprio de estudo da RFT e não os produtos desse comportamento. Nesse ponto há coincidência plena entre ambas abordagens.

\section{Herança ou Aprendizagem}

Contudo, para os proponentes da Teoria das Molduras Relacionais, o RRAA, é aprendido, como todo comportamento operante; enquanto a Língua I é considerada por Chomsky (2018) "uma propriedade biológica dos seres humanos, um subcomponente do cérebro (principalmente) um órgão da mente/cérebro no sentido vago em que o termo órgão é usado na Biologia” (p. 31). Um dos motivos que levam o pai da linguística moderna a sustentar essa posição consiste no fato de ter encontrado uma ampla diversidade de fenômenos que acontecem em todas as línguas da mesma forma. Nesse sentido, Chomsky (2018) afirma:

Em termos técnicos, as regras são invariavelmente dependentes da estrutura, ignorando a ordem linear. $\mathrm{O}$ enigma é entender por que a linguagem tem essa propriedade - não apenas o português ou o inglês, mas todas as línguas; e isso não funciona apenas com essas construções exemplificadas, mas também para muitas outras (p. 38).

Encontramos aqui uma profunda divergência que não pode ser minimizada. Mesmo que seja cabível argumentar que as propriedades do RRAA, a implicação mútua, a implicação mútua combinatória e a transformação de função são passíveis de serem adquiridas por causa da história filogenética da espécie humana, isso não significa que o RRAA não seja uma aquisição ontogenética, como claramente postulam Hayes et al. (2001): "A RFT abraça a simples ideia de que derivar relações de estímulo é um comportamento aprendido" (p.22). Essa divergência entre as abordagens, na verdade, revela diferenças profundas na concepção da Linguagem e do seu estudo científico.

\section{Base Epistemológica}

Chomsky (2018), pesquisador que se insere no amplo movimento cognitivista que surge a partir da década de 30, adota uma perspectiva internalizante. Esta perspectiva, de acordo com Bandini e de Rose (2010), se fundamenta em pressupostos filosóficos racionalistas. Esta filosofia tradicionalmente considerou as ideias de "mente" e "representação" como elementos fundamentais para a compreensão da natureza humana. Esse tema, de fato, é o assunto central do livro do linguista americano mais usado neste trabalho (Chomsky, 2018), que foi selecionado por se tratar de uma obra de maturidade (Bilgrami, 2018) e, consequentemente, representativa do seu pensamento atual. Neste livro, Chomsky (2018) retoma discussões seculares a respeito da relação mente-corpo, apresentando argumentos bastante sofisticados, mas de base claramente racionalista, como no trecho a seguir, a respeito da noção de referência: "a natureza peculiar pertencente aos elementos linguísticos usados para se referir não é algo externo e independente da mente" (Chomsky, 2018, p. 172).

Em completo contraste, a Ciência Comportamental Contextual é empírica e fundamentada em uma perspectiva epistemológica, o Contextualismo Funcional, de cunho radicalmente pragmático (Lewin et al., 2016). A aposta por um modelo de ciência contextualista implica na adoção de um critério de verdade de tipo pragmático (Hayes, 1993). O filósofo americano Stephen Pepper (1942) postulou que as diferentes perspectivas filosóficas acerca da natureza da realidade desenvolvidas ao longo da história do pensamento poderiam ser agrupadas em quatro grandes tipos: formismo, organicismo, mecanicismo e contextualismo. Cada uma dessas grandes "visões de mundo" se distingue das outras com base em duas caraterísticas: sua "metáfora raiz" e seu "critério de verdade". A metáfora raiz deve ser entendida como a analogia básica que é empregada, em cada visão de mundo, para entender e explicar a realidade. Por exemplo, no mecanicismo, a metáfora raiz é a máquina $e$, portanto, nessa perspectiva, seria possível descrever adequadamente a realidade concebendo diversas partes do real como peças de uma máquina que interagem com base a leis constantes. O critério de verdade pode ser definido como a medida de 
comparação que é proposta para decidir, em cada visão de mundo, se uma determinada proposição é verdadeira ou falsa. Tomando, de novo, o mecanicismo como exemplo, seu critério de verdade é a "verdade como correspondência", ou seja, seria verdadeira aquela proposição cujo significado se corresponde com o real estado de coisas no mundo. Como foi mencionado, a Ciência Comportamental Contextual adota um critério pragmático de verdade, frequentemente enunciado como "funcionamento efetivo". Isso significa que uma determinada análise será considerada verdadeira apenas se, por causa dela, são atingidos objetivos previamente estipulados. Portanto, há uma diferença notável entre o critério pragmático de verdade e o critério mecanicista (a verdade como correspondência), que recebeu fortes críticas, principalmente a respeito do seu uso nas ciências (e.g. Hayes, 1993).

\section{Considerações Finais}

Talvez pela acritude e o tom de algumas das suas críticas, como aponta MacCorquodale (1970), a Resenha de 1959 foi deliberadamente ignorada por Skinner. Outros analistas do comportamento, como o próprio MacCorquodale (1970), publicaram apenas textos apologéticos da obra skinneriana, mas não parece ter existido, desde a Análise do Comportamento, uma tentativa de aproximar posições com a proposta chomskyana para o estudo da Linguagem.

O desenvolvimento, dentro da tradição comportamental, de uma nova aproximação ao fenômeno da linguagem que apresenta diferenças significativas com aquela de Skinner (1957) pode tornar-se a ocasião para o início de um diálogo mais produtivo entre ambas abordagens ${ }^{1}$. A partir dessas considerações, uma análise foi realizada com o objetivo de identificar pontos de encontro entre ambas perspectivas e, também, pontos de desencontro ainda remanescentes. Entre os principais pontos de encontro,

1 A explicitação das diferenças entre a concepção skinneriana de linguagem e a proposta da RFT foge ao escopo do presente trabalho. Para tanto, consultar mas encontramos boas explicações em Hayes, Blackledge e Barnes-Holmes (2001) e em Barnes-Holmes, Barnes-Holmes, \& Cullinan (2000). cabe remarcar que a Teoria das Molduras Relacionais lida com a questão, fundamental na linguística chomskyana, da geratividade da linguagem de forma efetiva e específica, a diferença de tentativas anteriores que tendiam a explicar a produção de "respostas novas" recorrendo a processos não especificamente verbais. Em segundo lugar, há coincidência em ambas posições teóricas a respeito de caracterizar a linguagem como um comportamento típico da espécie humana, ao menos nas suas formas menos rudimentares. Um terceiro ponto de encontro ocorre pelo fato de Chomsky (2018) ponderar a existência de uma íntima relação entre Linguagem e Pensamento, que é uma proposta totalmente alinhada com a ideia da Teoria das Molduras Relacionais de considerar o RRAA como núcleo tanto da linguagem quanto da cognição propriamente humana. Um quarto motivo de convergência é a inserção autodeclarada de ambas perspectivas no âmbito das Ciências Evolutivas, ambas com princípios e métodos próprios, mas compartilhando os princípios básicos do paradigma evolucionista. Esta quarta caraterística, a diferença das três anteriores, poderia ter sido predicada também a respeito da proposta skinneriana. Finalmente, um quinto e último ponto em comum é a ênfase em estudar processos e comportamentos e não focar nos produtos desses processos e atividades.

Apesar da significância desse conjunto de possíveis pontos de aproximação entre o tratamento comportamental da Linguagem e a abordagem chomskyana, a maioria dos quais não teriam sido possíveis antes da formulação da Teoria das Molduras Relacionais, diversas questões de suma importância continuam mantendo a distância, e até a oposição, entre ambas. Em primeiro lugar, a diferente importância atribuída à filogenia e à ontogenia na determinação da linguagem por ambas teorias. Enquanto Chomsky assume uma posição claramente inatista, a Teoria das Molduras Relacionais considera a Linguagem, basicamente como comportamento aprendido. Essa diferença pode advir por causa de diferenças de natureza filosófica. Se por um lado a Teoria das Molduras Relacionais provém de uma tradição de pensamento empirista e pragmática, Chomsky está claramente alinhado com a tradição do racionalismo filosófico. Essa diferença epistemológica fundamental acarreta implicações a respeito das fontes de controle do 
comportamento (internas ao organismo no caso da posição racionalista e externas -ou ambientaisno caso da concepção empirista) e do critério de verdade. Finalmente, no lado negativo do balanço pode ser interessante acrescentar também o ceticismo expresso por Palmer (2006) a respeito da possibilidade de Noam Chomsky aceitar qualquer uma das propostas críticas com o "Comportamento Verbal" de Skinner surgidas no âmbito behaviorista, entre as quais se inclui a Teoria das Molduras Relacionais.

Se estas importantes diferenças podem ser de alguma forma superadas para benefício do avanço do conhecimento científico no campo da linguagem, apenas o futuro pode dizer. Contudo, dado que a RFT adota uma epistemologia de natureza pragmática, cabe o entendimento de que as diferenças conceituais entre ambas as abordagens possam, progressivamente, ser dirimidas com base em pesquisas empíricas que permitam testar as hipóteses conflitantes. Esperamos que este trabalho seja uma contribuição, embora modesta, nessa direção.

\section{Referências}

Austin, J. L. (1962). How to do things with words. Harvard University Press. (Obra original publicada em 1955).

Bandini, C. S. M., de Rose, J. C. (2010). Chomsky e Skinner e a polémica sobre a geratividade da linguagem. Revista Brasileira de Terapia Comportamental e Cognitiva. XII(1), 20-42. https://doi.org/10.31505/rbtcc.v12i1/2.414

Barnes-Holmes, D., Barnes-Holmes, Y., \& Cullinan, V. (2000). Relational frame theory and Skinner's Verbal Behavior: A possible synthesis. The Behavior Analyst, 23(1), 69-84.

Biglan, A. (2016). A Functional Contextualist Approach to Cultural Evolution. In R. D. Zettle; S.C. Hayes; D. Barnes-Holmes \& A. Biglan (Eds.), The Wiley Handbook of Contextual Behavioral Science (pp. 385-397). John Wiley \& Sons, Ltd.

Bilgrami, A. (2018). Prefácio. In N. Chomsky, Que tipo de criaturas somos nós? (pp. 7-25.) (Gabriel de Ávila Othero \& Luisandro Mendes de Souza, trads.) Editora Vozes.

Blackledge, J.T. (2003). An introduction to Relational Frame Theory: Basics and Applications. The Behavior Analyst Today. 3(4), 421-432, http://doi.org/10.1037/h0099997.

Chomsky, N. (1959). A Review of B. F. Skinner's Verbal Behavior. Language, 35(1), 26-58. https://doi.org/10.4159/harvard.9780674594623. c6

Chomsky, N. (2018). Que tipo de criaturas somos nós? (Gabriel de Ávila Othero \& Luisandro Mendes de Souza, trads.). Editora Vozes.

Day, W. F. (1969). On certain similarities between the Philosophical Investigations of Ludwig Wittgenstein and the Operationism of B. F. Skinner. Journal of the Experimental Analysis of Behavior. 12(3), 489-506. https://doi. org/10.1901/jeab.1969.12-489

De Houwer, J. (2013). Foreword. E, S. Dymond \& B. Roche (Eds.), Advances in Relational Frame Theory (pp. 5-26). Context Press.

Dougher, M. J., Hamilton, D. A., Fink, B. C., \& Harrington, J. (2007). Transformation of the discriminative and eliciting functions of generalized relational stimuli. Journal of the 
Experimental Analysis of Behavior, 88, 179-197. https://doi.org/10.1901/jeab.2007.45-05

Dube, W. V., McIlvane, W. J., Callahan, T. D., \& Stoddard, L. T. (1993). The search for stimulus equivalence in nonverbal organisms. The Psychological Record, 43(4), 761-778. https:// doi.org/10.1007/BF03395911

Eldredge, N. \& Gould, S. J. (1972). Punctuated equilibria: an alternative to phyletic gradualism. Em T.J.M. Schopf (Ed.), Models in Paleobiology (pp. 82-115). Princeton University Press.

Escandell Vidal, M. V. (2018). El lenguaje y la lingüística. Em M.V. Escandell Vidal (Ed.), Claves del Lenguaje Humano (pp. 1-32). Editorial Universitaria Ramón Areces.

Hayes, S. C. (1987). Language and the incompatibility of evolutionary and psychological continuity. Behavior Analysis, 22(2), 49-54. https://contextualscience.org/publications/hayes_1987_1

Hayes, S. C. (1989). Nonhumans have not yet shown Stimulus Equivalence. Journal of the Experimental Analysis of Behavior, 51(3), 385292. https://doi.org/ 10.1901/jeab.1989.51-385

Hayes, L. (1993). Reality and Truth. Em S. C. Hayes, L. Hayes, H. W. Reese \& T. R. Sarbin (Eds.) Varieties of Scientific Contextualism (pp. 3550). Context Press.

Hayes, S. C., Barnes-Holmes, D., \& Roche, B. (2001). Relational Frame Theory: a post-skinnerian account of human language and cognition. Kluwer Academic Publishers.

Hayes, S. C., Blackledge, J. T., \& Barnes-Holmes, D. (2001). Language and cognition: Constructing an alternative approach within the behavioral tradition. Em Hayes, S. C., Barnes-Holmes, D., \& Roche, B. (2001). Relational Frame Theory: a post-skinnerian account of human language and cognition (pp. 3-20). Kluwer Academic Publishers

Hayes, S. C., Fox, E., Gifford, E. V., Wilson, K. G., Barnes-Holmes, D., \& Healy, O. (2001). Derived Relational Responding as Learned Behavior. Em S.C. Hayes; D. Barnes-Holmes \& B. Roche (Eds.), Relational Frame Theory: a Post-Skinnerian Account of Human Language and Cognition (pp. 3-20). Kluwer Academic Publishers.

Hayes, S. C., Barnes-Holmes, D., \& Wilson, K. G. (2012). Contextual Behavioral Science: crea- ting a science more adequate to the challenge of the human condition. Journal of Contextual Behavioral Science, 1, 1-16. https://doi. org/10.1016/J.JCBS.2012.09.004

Hayes, S. C., \& Long, D. M. (2013). Contextual Behavioral Science, Evolution, and Scientific Epistemology. Em S. Dymond \& B. Roche (Eds.), Advances in Relational Frame Theory (pp. 5-26). Context Press.

Hayes, S. C., \& Sanford, B. T. (2014). Cooperation came first: Evolution and human cognition. Journal of the Experimental Analysis of Behavior, 101, 112-129. https://doi.org/10.1002/jeab.64

Hughes, S., \& Barnes-Holmes, D. (2014). Associative concept learning, stimulus equivalence, and relational frame theory: Working out the similarities and differences between human and non-human behavior. Journal of the Experimental Analysis of Behavior, 101(1), 156160. https://doi.org/10.1002/jeab.60

Levin M. E., Twohig, M. P. \& Smith, B. M. (2016). Contextual Behavioral Science: An Overview. Em R.D. Zettle, S.C. Hayes, D. Barnes-Holmes \& A. Biglan (Eds.), The Wiley Handbook of Contextual Behavioral Science (pp. 17-36). John Wiley \& Sons, Ltd.

MacCorquodale, K. (1970). On Chomsky's review of Skinner's Verbal Behavior. Journal of the Experimental Analysis of Behavior. 13(1), 8399. https://doi.org/10.1901\%2Fjeab.1970.13-83

McIntire, K. D., Cleary, J., \& Thompson, T. (1987). Conditional relations by monkeys: Reflexivity, symmetry, and transitivity. Journal of the Experimental Analysis of Behavior, 47, 279-285. https://doi.org/10.1901/jeab.1987.47-279

Monestès, J. L. (2016). A Functional Place for Language in Evolution: The Contribution of Contextual Behavioral Science to the Study of Human Evolution. In R. D. Zettle; S.C. Hayes; D. Barnes-Holmes \& A. Biglan (Eds.), The Wiley Handbook of Contextual Behavioral Science (pp. 100-114). John Wiley \& Sons, Ltd.

Palmer, D. C. (2006). On Chomsky's appraisal of Skinner's Verbal Behavior: A half century of misunderstanding. The Behavior Analyst. 29(2), 253-267. https://www.doi.org/10.1007/ BF03392134 
Pepper, S. C. (1942/1972). World hypotheses: A study in evidence. California University Press.

Skinner, B. F. (1984). Selection by consequences. Behavior and Brain Sciences, 7(4), 477-481. https://doi.org/10.1017/S0140525X0002673X

Skinner, B. F. (1945/1984). The operational analysis of psychological terms. Behavior and Brain Sciences, 7, 547-553 (trabalho originalmente publicado em 1945). https://doi.org/10.1037/ h0062535

Skinner, B. F. (1957). Verbal Behavior. Copley Publishing Group.

Vaughan, W. (1988). Formation of equivalence sets in pigeons. Journal of Experimental Psychology: Animal Behavior Processes, 14(1), 36-42. https://doi.org/10.1037/0097-7403.14.1.36

Wittgenstein, L. (1968). Tractatus LogicoPhilosophicus. Trad. Jorge Arthur Giannoti. Companhia Editora Nacional. Editora da Universidade de São Paulo. (Obra original publicada em 1922).

Wittgenstein, L. (2014). Investigações filosóficas. Trad. Marcos G. Montangoli. Editora Universitária São Francisco. (Obra original publicada em 1953). 